\title{
A Pragmatic-Semantic Study of Colour Symbolism in English and Arabic Literary Texts
}

\author{
Asst. Prof. Qasim Abbas Dhayef PhD
}

qasimabbas@uobabylon.edu.iq. Department of English, College of Education for Human Sciences, University of Babylon

\section{Noor Al-Huda Kadhim Hussein}

alhusseininoor688@gmail.com. PhD Student, Department of English, College of Education for Human Sciences, University of Babylon

\begin{abstract}
Symbolism in general and colour symbolism in particular have not received the linguists' attention in the same way studied by literary critics. Thus, the present study is an attempt to limit this gap by studying colour symbolism linguistically to answer the following questions: (1) What is the most flouted maxim in colour symbolism in literary texts in English and Arabic? (2) Is colour symbolism context-dependent in literary texts? (3) What are the semantic aspects of colour symbolism in the literary texts selected? Thus, the present study aims at: (1) Pinpointing the most flouted maxim in colour symbolism in literary texts in English and Arabic. (2) Determining whether colour symbolism is context-dependent in literary texts. (3) Investigating he semantic aspects of colour symbolism in the literary texts selected. To achieve its aims, the present study hypothesizes that: (1) The maxim of manner is the most flouted maxim in colour symbolism in English and Arabic literary texts. (2) Colours symbolize different things in different contexts. (3) There are certain semantic aspects for colour symbolism manipulated in the literary texts such as using metaphor and conveying the connotative meaning of colours. Then, in order to achieve the aims of the study and test its hypotheses, the following procedures are adopted: (1) Presenting a theoretical background about colour symbolism in general and colour symbolism from a linguistic point of view. (2) Analyzing (six) extracts of literary texts according to an eclectic model based on Eco's (1984) model Semiotics and the Philosophy of Language and some semantic aspects. The data of the present study is collected from Nathaniel Hawthorne and Wassini Al-A'erj novels "The Scarlet Letter" and "انثى السراب" Ontha Al Sarab" respectively. The study has come up with certain conclusions that prove the above set hypotheses.
\end{abstract}

Keywords:

Linguistic Symbolism, Colour Symbolism, Literary Texts Nathaniel Hawthorne, Wassini Al-A'erj

Article Received: 18 October 2020, Revised: 3 November 2020, Accepted: 24 December 2020

\section{Introduction}

For years, writers have used the concept of colour as a symbol to help readers get a better understanding of characters, events, and ideas. By utilizing colour symbolism, they infuse deeper meaning into something and create something more memorable for readers by attaching an emotional state or event or even character to a colour.

Etymologically, the word symbolism originated from the verb 'symballein' which means "to throw together", which in turn is derived from the Greek word 'symbolon' and the Latin one 'symbolum' meaning sign token, emblem or mark (Cuddon,
1999: 884). The term is used in many disciplines. In the broad sense, Susan Stebbing (1930) defines a symbol as a "sign consciously designed to stand for something", or it is anything that symbolises or signifies something else. According to this definition, linguists view all words as symbols regardless of their meaning or usage. For example, the word 'bird' represents a bird, but the word is not itself a bird (Markovic, 1984: 94).

In literature, as Abrams and Harpham (2009: 358) state, the term is applied only to "a word or phrase that signifies an object or event which in its turn signifies something, or suggests a range of reference, beyond itself". Similarly, Kirszner and 
Mandell (1994: 259) define it as "a person, object, action, place, or event that in addition to its literal or denotative meaning suggests a more complex meaning or range of meanings". Cuddon (1999: 884 ) notes that not only objects or animates can stand for or represent something else, gestures and actions can also be symbolic for example raising arms symbolises surrender and beating the breast denotes remorse. So, writers use symbols to enrich meaning and to enable the reader to interact with the text and go further looking for possible interpretations of the text in addition to its interpretation on the literal level; that is to say, symbols expand the possibilities of interpretation of a particular text.

On his part, Alhaj (2015: 10) defines symbolism as "a kind of figures of speech used for increasing the beauty of the text and has figurative meaning besides its literal meaning".

Symbolism is a term used in many disciplines. In the broad sense, Susan Stebbing (1930) defines a symbol as a "sign consciously designed to stand for something", or it is anything that symbolises or signifies something else (Markovic, 1984: 94).

Linguistically, symbolism is one of the linguistic figures of speech that forces the reader to make an imaginative leap to comprehend the writer's point. It performs an important function in literary discourse.

\section{Types of Symbols}

Abrams and Harpham (2009: 358) draw a distinction between two types of literary symbols:

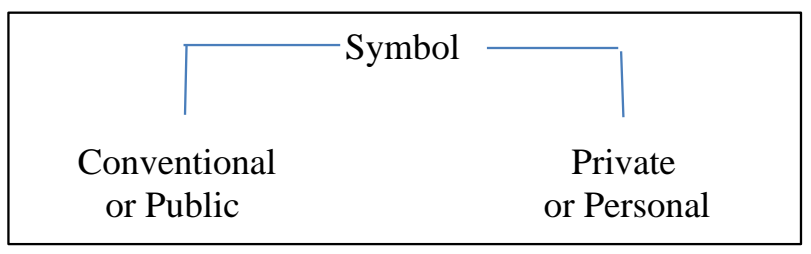

Figure (1): Types of Literary Symbols

\subsection{Conventional or public symbols}

They refer to those symbols which form part of human experience that they have the same association and represent the same thing to most people (who share the same social and cultural assumptions). A rose, for example, represents love. This type of symbols enables the writer to convey his emotions and ideas with a high degree of reliability because he is confident that the readers, who share his frame of reference, will get the idea he is conveying. Another good example is the use of autumn as an image to communicate declining years and powers (Kirszner and Mandell, 1994: 259).

\subsection{Private or Personal symbols}

This type of symbols, in addition to having the same association or meaning for most people, may derive additional indeterminate meaning that could be interpreted only in the specific context in which it is used, i.e. the particular literary work. For example, a watch might suggest multiple meanings in a particular story that in addition to denoting time, it might communicate other meanings like the passing of time or it might stand for the character's inability to bring back the past and so on. The same thing holds true with actions, events, characters and places (ibid.).

\section{Colour and Culture}

According to Blair and Bloom ( 2011:25) "colours could mean whatever people wanted them to mean." Accordingly colour is viewed in each culture and civilization differently.

Scholars have long struggled to understand the nature of colour, the cultural role it plays in our lives, in universal experience, in art, and as a metaphor for emotions. Understanding the nature of colour, however, has proved an overwhelming task. Colours can mean extremely different things; this is not because colors themselves have meaning, but because language users have culturally assigned meanings to them. For example, white in Hinduism is a mark of mourning and widows are expected to dress in white in order to show their grief, while red is the traditional bridal dress. Black is a multidimensional color that can mean classic or new. It has the ominous characteristic symbolizing death. Therefore, it is used in Western cultures for 
funerals. Red is the color of celebration and good luck (China), purity and integrity (India), and mourning (South Africa). Red is also the color of the devil in modern Western culture. Colour symbolism is actualized in all walks of life and is seen in almost all fields of knowledge (web Resource).

\section{Methodology}

Colour Symbolism in the literary texts selected is carried out according to an eclectic model based on Eco's (1984) model Semiotics and the Philosophy of Language. This model approaches symbolism pragmatically.

The present study aims at analyzing colour symbolism linguistically according to an eclectic model based on Eco's (1984) model Semiotics and the Philosophy of Language. This model approaches symbolism pragmatically. According to this model, symbolism is a type of textual implicature generated by non-observance of one or more of Grice's maxims or by a deviation from the textual norm. That prompts the reader to overencode and explore the possible meaning or interpretation. In this way, Grice's four maxims are the base for this model. Hence, for each selected extract of the novels, Grice's cooperative principle is examined to show to what extent the writer and the characters exploit the maxims of quantity, quality, relation, and manner to convey ideas and messages indirectly by means of colour symbolism.

Semantic components are added to the model such as the metaphor as a semantic literary device and the connotative meaning of each colour utilized in the literary texts selected. This model will be the main instrument by which the data of this study is analyzed as shown in figure (2):

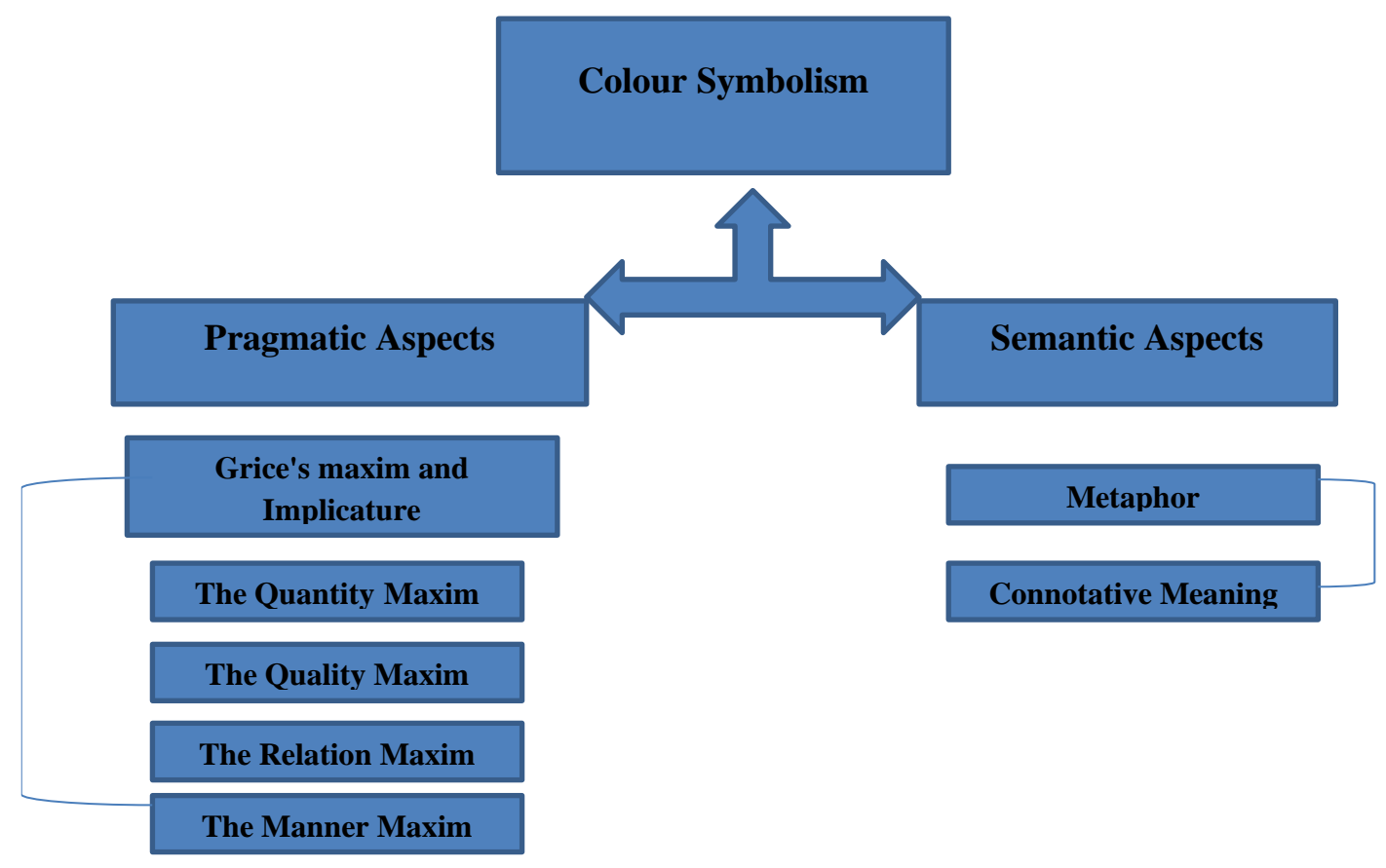

Figure (2): The Model of Analysis

\section{Data of Analysis}

The data of the present study is selected from Nathaniel Hawthorne and Wassini Al-A'erj novels "The Scarlet Letter" and "انتى السراب" Ontha Al
Sarab" respectively. From each novel three extracts are analyzed. Although many colours are manipulated in these two novels, the symbolism of 
only three colours are considered red, black and gray to unify the analysis of the study.

\section{Analysis of Data}

The analysis is both qualitative and quantitative. For each extract the sematic and pragmatic aspects are approached to investigate the way the writers manipulate colours symbolism to generate deeper meanings and interpretations.

\section{Extract (1)}

"Before this ugly edifice, and between it and the wheel-track of the street, was a grass-plot, much overgrown with burdock, pigweed, apple-peru, and such unsightly vegetation, which evidently found something congenial in the soil that had so early borne the black flower of civilized society, a prison."(Chapter 1, Page 35)

Metaphorically, the writer uses the black colour in "the black flower of civilized society" to symbolically refer to the seed of sin in the heart of nature. The image of the colour here is a negative image and, thus, negative connotation. However, by means of this semantic device, the result is an extended metaphor about the hopeful ending of the story that helps the reader to understand that even in the midst of the intolerance, oppression and darkness, there is hope and light.

Since metaphorically this image is delivered, the maxims of quantity, quality and manner are flouted in the above extract as what is said in relation to colour symbolism is not as informative as required, not true and lacks clarity as well.

\section{Extract (2)}

"“Pearl?-Ruby, rather!-or Coral!-or Red Rose, at the very least, judging from thy hue!" responded the old minister, putting forth his hand in a vain attempt to pat little Pearl on the cheek." (Chapter 8, Page 83)

In this extract, the writer makes use of the symbolism of the red colour. Metaphorically, the red rose here symbolizes sin and evil as the red colour has a negative connotation. In this context, implicature is generated by means of symbolism as the red colour which Pearl wears is reminder to both Hester and Dimmesdale of the sin they have committed, i.e. the outward appearance of sin and evil.

On the semantic level, the writer makes use of metaphor to convey this image to enable the reader to make an imaginative leap and expand the possibilities of interpretation of such image. In this way, pragmatically, and by means of the character conversational contribution, the writer flouts the three maxims: quantity (by not being as informative as required), quality (as the conversational contribution is the one that is not true) and manner (since the conversational contribution is not clear and ambiguous).

\section{Extract (3)}

"As if there were a withering spell in the sad letter, her beauty, the warmth and richness of her womanhood, departed, like fading sunshine; and a gray shadow seemed to fall across her." (Chapter 19, Page 163)

By means of metaphor, as a semantic device, the writer makes use of the gray colour to symbolizes Hester's sadness, social and psychological pressure and heavy responsibility. Thus, the gray colour in this context has a negative connotation.

Again, the maxims of quality and manner are flouted by the writer since what he is saying is not true (as far the quality maxim is concerned) and the message he conveys lacks clarity (in which the maxim of manner is affected).

\section{Extract (4)}

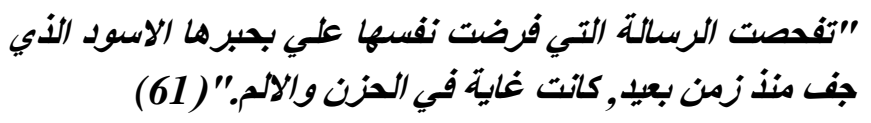

Most of the connotation that are related to the black colour are the negative ones. Thus, this colour is manipulated symbolically by the writer for conveying a deeper meaning whose connotation is negative. In this context, it stands for Sorrow, sadness, depression, and frustration. So, by flouting the maxim of manner, through the 
character's conversational contribution, the writer generates implicature and, thus, symbolism by means of manipulating the black colour in an obscure manner.

\section{Extract (5)}

\section{"لم ار الا نقاط حمراء................ تتراقص على خلفية

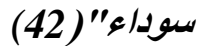

Colours are not only culture specific, they are context dependent. Generally, the red colour refers to love, passion and energy. In this extract, however, it is manipulated symbolically by the writer through his character's conversational contribution in "نقاطا حمر to stand for danger, blood and death. The maxim of manner is flouted through this symbolic manipulation as the meaning cannot be pinned down and the choice of the interpretation is left for the reader to decide upon. Again, the black colour is manipulated in "خلفية سوداء" to symbolize death and the sad end of the character. Symbolism, in this contexts, also affects the maxim of manner by lacking the clarity 7. Discussion of Results of expression. Semantically, the two colours, in this context, have negative connotation.

\section{Extract (5)}

"ولكن كل شسي صار رماديا ومرا, لا غيم بكفنه الا السواد

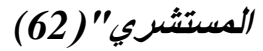

In this extract, two colours are manipulated by the writer symbolically. The first one is the gray colour in "صار رماديا" (became gray) to pragmatically communicate something on a deeper level by means of the semantic device metaphor to refer to sadness, death and fading away. The maxims of quality and manner are flouted in this context. The same thing holds true with the two maxims in the reference to the second colour the black in "السواد المستشري", (the spread black) Semantically, the semantic device metaphor is applied twice with the two colours conveying negative connotation.

Table (1) Frequency and Percentage of the Linguistic Aspects of Colour Symbolism

\begin{tabular}{|c|c|c|c|c|c|c|}
\hline \multirow{2}{*}{$\begin{array}{c}\text { No } \\
\text { of }\end{array}$} & \multicolumn{4}{|c|}{ Flouting of Grice's Maxims } & \multicolumn{2}{c|}{ Semantic Aspects } \\
\cline { 2 - 7 } & Quantity & Quality & Relation & Manner & Metaphor & Connotation \\
$+/-$ & & \\
\hline$(1)$ & 1 & 1 & 0 & 1 & 1 & - \\
\hline$(2)$ & 1 & 1 & 0 & 1 & 1 & - \\
\hline$(3)$ & 0 & 1 & 0 & 1 & 1 & - \\
\hline$(4)$ & 0 & 0 & 0 & 1 & 0 & - \\
\hline$(5)$ & 0 & 0 & 0 & 2 & 0 &,-- \\
\hline$(6)$ & 0 & 2 & 0 & 2 & 2 &,-- \\
\hline Percentage & $13.3 \%$ & $33.3 \%$ & $0 \%$ & $53.3 \%$ & $/$ & $/$ \\
\hline
\end{tabular}

As far as the findings of the analysis are concerned, the above table shows that the maxim of manner is the most flouted maxim in colour symbolism in the literary texts selected making
(53.3\%). This is related to the way the colours symbolism are delivered to the reader. It lack clarity, i.e. either vague or ambiguous. As for the semantic aspects of colour symbolism, metaphor 
is the only semantic device manipulated for symbolic meanings. It is manipulated five times (three in the English novel and twice in the Arabic one). As for the connotation of the colours manipulated, the three colours in all of the contexts they occur convey negative connotation to the reader.

\section{Conclusions:}

The study has come up with the following conclusions:

1. Pragmatically, the maxim of manner is the most flouted maxim in both the English and Arabic literary texts. This proves hypothesis No.1 which reads as The maxim of manner is the most flouted maxim in colour symbolism in English and Arabic literary texts.

2. Colour symbolism is context-dependent. Its symbolic meaning is related to the way the writer manipulates it the literary text to symbolize something and communicate meanings. This proves hypothesis No. 2 which reads as Colours symbolize different things in different contexts.

3. Semantically, metaphor is the only employed semantic device in colour symbolism in the literary texts selected.

4. Although colours symbolic meanings are culture-specific, there are common aspects shared by the symbolism of the colours employed in the novels such as the negative connotations delivered by the writer. This conclusion, along with the previous one, prove hypothesis No. 3 which reads as: There are certain semantic aspects for colour symbolism manipulated in the literary texts such as using metaphor and conveying the connotative meaning of colours.

\section{References}

[1] Abrams, M. H. and Harpham, G. G. (2009). A Glossary of Literary terms.Boston: Wadsworth Cengage Learning.
[2] Alhaj, A. (2015). Symbolism in Selected Novels F. Scott. Fitzgerald's. Germany: Anchor Academic Publishing.

[3] Black, E. (2006). Pragmatic Stylistics. Edinburgh: Edinburgh University Press Ltd.

[4] Bloom, Jonathan and Sheila Blair. "Introduction: Color in Islamic Art and Architecture", in And Diverse Are Their Hues: Color in Islamic Art and Culture, ed. Jonathan M. Bloom and Sheila S. Blair (London, 2011), 1-51.

[5] Cuddon, J.A. 1999. The Penguin Dictionary of Literary Terms and Literary Theory. London: Penguin Books.

[6] Eco, U. (1984). Semiotics and the Philosophy of Language. Basingstoke: Macmillan.

[7] Kirszner, L. G. and Mandell, S. R. (1994). Fiction: Reading, Reacting, Writing. Fort Worth: Harcourt Brace College Publishers.

[8] Markovic, M. (1984). Dialectical Theory of Meaning. Boston: D. Reidel Publishing.

[9] Hawthorne, N. (1851). The Scarlet Letter. London: Walker.

[10] Web Resource :http://en.wikipedia.org/wiki/Color_psych ology): accessed in 4/12/2020

\section{Arabic Reference:}

$$
\text { دار الآداب. واسيني. (2010). أنثى السراب. لبنان-بيروت: }
$$

